\title{
Results of the National Program for the Prevention of Blindness in Childhood by Retinopathy of Prematurity in Argentina (2004-2016)
}

\author{
Ernesto Alda, M.D., Celia C. Lomuto, M.D., Alicia M. Benítez, M.D., \\ Liliana Bouzas, M.D., Marina Brussa, M.D., Adriana Cattaino, M.D., \\ N. Alejandro Dinerstein, M.D., Norma Erpen, B.S., Lidia Galina, M.D., \\ Celeste Mansilla, M.D., Silvia Marinaro, M.D., Ana Quiroga, B.S., Gabriela Saidman, M.D., \\ Celia Sánchez, M.D., Teresa Sepúlveda, M.D., and Patricia Visintin, M.D.
}

\begin{abstract}
Introduction. The ROP Argentina Group was created in 2003 and is responsible for the National Program for the Prevention of Blindness in Childhood by Retinopathy of Prematurity (ROP) in Argentina.

Objectives. To describe the program implementation and results achieved in relation to ROP care in terms of effectiveness, access, and quality (2004-2016).

Population and methods. Descriptive, retrospective study with a dynamic cohort carried out in facilities that are part of the registry. Eligible population: All preterm newborn infants with risk factors for ROP.

Results. Participating health care services increased from 14 to 98 and covered the 23 provinces and the Autonomous City of Buenos Aires. A total of 956 infants were born with < $1500 \mathrm{~g}$ in 2004 and 2739, in 2016. Of these, $22.7 \%$ had some degree of ROP and $7.8 \%$ required treatment (severe ROP). Vision screening exceeded $90 \%$, and treatments at the place of origin increased $(57 \%-92 \%)$. The incidence of unusual cases is still high (17.3\% of treated cases), and missed opportunities are still recorded. The use of anti-angiogenic drugs trebled since 2011, when they started to be used. Conclusions. Significant achievements were observed in terms of program representativeness, scope, and adherence, and also in relation to screening access and treatment at the place of origin; however, the incidence of ROP is still missed opportunities evidences deficiencies in the quality of health care and outpatient follow-
\end{abstract}

E-mail address:

Ernesto Alda, M.D.: eralda@criba.edu.ar

Funding:

Ministry of Health, United Nations International Children's Emergency Fund (UNICEF), Pan American Health Organization (PAHO)/ World Health Organization (WHO).

Conflict of interest: None.

Received: 2-28-2018 Accepted: 5-28-2018 up and underlines the need to strengthen the program actions in relation to services.

Keywords: retinopathy of prematurity, neonatology, ophthalmology, epidemiology, prematurity.

http:/ / dx.doi.org/10.5546/ aap.2018.eng.386

To cite: Alda E, Lomuto CC, Benítez AM, Bouzas L, et al. Results of the National Program for the Prevention of Blindness in Childhood by Retinopathy of Prematurity in Argentina (20042016). Arch Argent Pediatr 2018;116(6):386-393.

\section{INTRODUCTION}

Retinopathy of prematurity (ROP) is a central nervous system disease caused by an alteration in the vascularization of the retina, which may affect its normal development and cause complete or partial visual loss. It affects only preterm infants, especially those born with a birth weight (BW) of $<1500 \mathrm{~g}$ and / or $\leq 32$ weeks of gestational age (GA). However, it may occur in older preterm infants, known as unusual cases, who are exposed to risk factors for ROP (oxygen $\left[\mathrm{O}_{2}\right]$ exposure,

ROP Argentina Group: Collaborative, multicenter task force for the prevention of blindness in childhood due to retinopathy of prematurity (ROP).

National Board of Maternity, Childhood, and Adolescence (Dirección de Maternidad, Infancia y Adolescencia, DINAMIA), National Ministry of Health of Argentina, Autonomous City of Buenos Aires, Argentina.

Participating societies: Argentine Society of Pediatrics (Sociedad Argentina de Pediatría, SAP), Committee for Fetal and Neonatal Studies (Comité de EstudiosFeto-neonatales, CEFEN). Argentine Council of Ophthalmology (Consejo Argentino de Oftalmología, CAO). Argentine Society of Pediatric Ophthalmology (Sociedad Argentina de Oftalmología Infantil, SAOI). 
intrauterine and postnatal growth restriction, sepsis, blood transfusions, surgeries). At present, ROP is considered a parameter of perinatal and neonatal health care quality. ${ }^{3}$

The ROP Argentina Group, advisory body for the National Board of Maternity, Childhood, and Adolescence (Dirección Nacional de Maternidad, Infancia y Adolescencia, DINAMIA) of the National Ministry of Health of Argentina, was created by Secretarial Resolution no. 26/2003. ${ }^{2}$ Since 2010, it has coordinated the National Program for the Prevention of Blindness in Childhood by Retinopathy of Prematurity in Argentina (Ministerial Resolution no. 1613/2010).

It is made up of nurses, neonatologists, and pediatric ophthalmologists representing DINAMIA and related scientific societies (Argentine Society of Pediatrics [SAP], Argentine Council of Ophthalmology [CAO], Argentine Society of Pediatric Ophthalmology [SAOI]). Most of them have done honorary work since the Group was created.

The main initial objectives were to address the need to have an updated, periodic diagnosis of the state of ROP in Argentina, create a registry -nonexistent until that time (2003)-, and carry out appropriate actions to improve outcomes. ${ }^{2}$

An intervention program was developed and implemented in neonatal intensive care units (NICUs) to emphasize on ROP prevention. In 2004, a network of neonatology services was established based on their level of care. A neonatologist, an ophthalmologist, and a nurse were designated as "ROP leaders" at each facility, and they were responsible for keeping registries and training the rest of the health care team. In the beginning, the registry only collected information on the number of live births (LBs) at each facility, data on infants with some degree of $\mathrm{ROP}$, and those who required treatment. In 2008, all infants at risk for ROP were included and, as of 2013, an online registry has been launched and updated: http: / / datos. dinami.gov.ar/produccion/rop/login.html. The central information point is located at DINAMIA and monitored by the coordinator of the ROP Argentina Group (CL).

The program was externally assessed in May 2008 by two methodologists from the Epidemiological Research Institute of the National Academy of Medicine of Argentina to establish its relevance and the actions carried out so far.

The main task of the ROP Argentina Group is to provide logistics and teaching support to the program participating services, mainly to those where the rate of severe ROP is above the national mean as determined by the reported surveillance.

In addition, ophthalmologists were trained on diagnosis and treatment at national facilities with broad experience in ROP; this allowed to approach newborns on site, thus bringing the imaginable benefits of reducing transportassociated morbidities.

In 2012, a clinical practice guideline (CPG) was developed based on the most updated systems to select the best scientific evidence on ROP prevention, diagnosis, and treatment. The CPG was completed in 2015 and was then translated into English for international dissemination.

After 13 years, the ROP Argentina Group presents the results of the national program and assesses the extent of its implementation.

\section{OBJECTIVES}

\section{General objectives}

- To describe the scope of the program implementation and results in relation to ROP care in terms of effectiveness, access, and quality between 2004 and 2016.

\section{Specific objectives}

- To describe the progress of the ROP registry in terms of representativeness, scope, and adherence.

- To describe the progress of the program results at the participating facilities based on ROP incidence, severe ROP forms, and risk factors.

- To describe geographic access to diagnosis and treatment practices in the population at risk.

- To describe the incidence of health care quality markers: unusual cases and missed opportunities.

\section{POPULATION AND METHODS}

Design: descriptive, retrospective study with a dynamic cohort made up of newborns, carried out in facilities participating in the ROP registry during the study period.

Eligible population: all preterm infants who survived beyond 28 days with risk factors for ROP. Study population: BW $<1500 \mathrm{~g}$ and / or $\leq 32$ weeks of GA and those defined as unusual cases.

\section{Main outcome measures}

The extent of implementation was assessed by means of the following: a. representativeness of the population covered by the ROP registry among the eligible population at a national 
level (number of provinces participating in the registry; total number of LBs in facilities adhered to the ROP program, relation to LBs at a national level); $\mathbf{b}$. adherence of neonatology services to the ROP program (active ROP leaders and data input into the registry); c. estimated scope based on the annual number of preterm infants at risk, admitted since the registry started in 2004 . The measurement of these outcome measures was based on the program database and the data provided by the Health Statistics and Information Department (Dirección de Estadística e Información en Salud, DEIS).

Effectiveness, access, and quality of health care were assessed in the cohort of preterm infants covered by the program since 2008 . Effectiveness was measured by means of the following: a. incidence of risk factors for ROP: BW, GA; b. incidence of ROP and severe ROP. Access was measured based on the number of preterm infants with risk factors for ROP who received diagnosis and treatment at the place of origin. The quality of ROP care was assessed based on the incidence of unusual cases and missed opportunities (blind children in the first eye examination).

Bioethical aspects: Given the study epidemiological characteristics, it was not necessary to obtain a committee's approval to this end.

\section{RESULTS}

\section{Program implementation}

Representativeness: In 2016, the participating facilities registered $227138 \mathrm{LBs}$, which accounted for $29.4 \%$ of all LBs in Argentina (LBs: 770 040) and for $51.3 \%$ of births occurring in the public sector facilities (LBs: 442 571). In 2016, at least one facility from every Argentine province was participating in the program (Figure 1).

Adherence: In 2016, 98 neonatology services submitted their registry ( 85 from public facilities and 13 from social security and private facilities). The number of participating facilities since 2004 are shown in Figure 1.

Scope: In 2016, 8318 preterm infants had risk factors for ROP; of these, 2739 had a BW of $<1500 \mathrm{~g}$ and survived past 28 days of life (Figure 2). In the $<1500$ g group, 622 newborns $(22.7 \%)$ had some degree of ROP, and $214(7.8 \%)$ required treatment (Figure 3).

\section{Program effectiveness}

Risk factor incidence: The average BW and GA of treated children reduced over the years. In 2004, the mean BW was 1310 g; in 2016, it was $1083 \mathrm{~g}(-227 \mathrm{~g})$. The average GA also showed a reduction: from 31 to 28 (-3 weeks). Intrauterine growth restriction (IUGR) was more common among unusual cases $(9.5 \%-16 \%)$.

ROP severity: In 2016, among ROP diagnosed cases, 429 corresponded to grade $1(51.7 \%) ; 268$, to grade $2(32.3 \%) ; 108$, to grade $3(13 \%) ; 2$, to grade $4 / 5(0.2 \%)$; and 22 , to aggressive posterior (AP) $\mathrm{ROP}(2.7 \%)$, which is a severe type that requires early treatment for impending retinal detachment.

The incidence of severe ROP among newborns

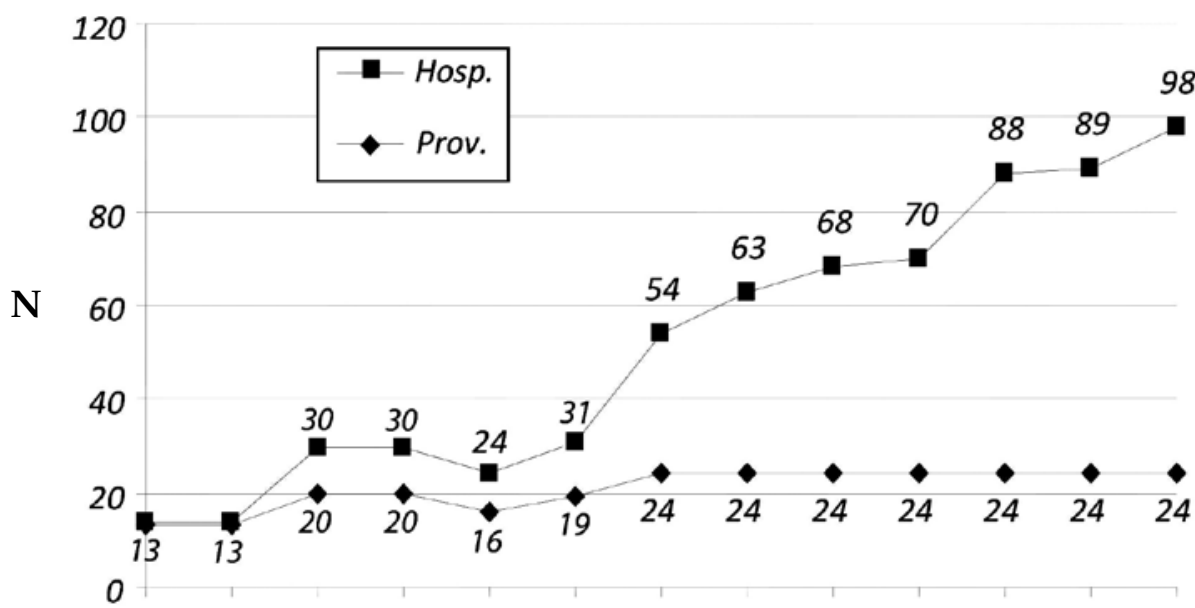

2004200520062007200820092010201120122013201420152016 
with a BW < $1500 \mathrm{~g}$ was $7.8 \%$ (Figure 3); such average was exceeded in a third of program participating services in 2016 (34/98).

\section{Access to ROP care}

Population accessibility to diagnosis and treatment at the place of origin: In average, a vision screening was done in $89 \%$, with a median of $91 \%$ (interquartile range [IQR]: 78-100\%).

In 2004, only half of newborns with severe ROP $(52 \%)$ were treated in the same service where they were diagnosed; in 2016, $92 \%$ of newborns were treated in the participating hospitals.

The use of intravitreal anti-angiogenic drugs (bevacizumab) began in 2011 and has increased fivefold over 5 years (from $5 \%$ to $26 \%$ ).

FIGURE 2. Total registries of newborns at risk for retinopathy of prematurity and number of newborns with a birth weight $<1500 \mathrm{~g}$

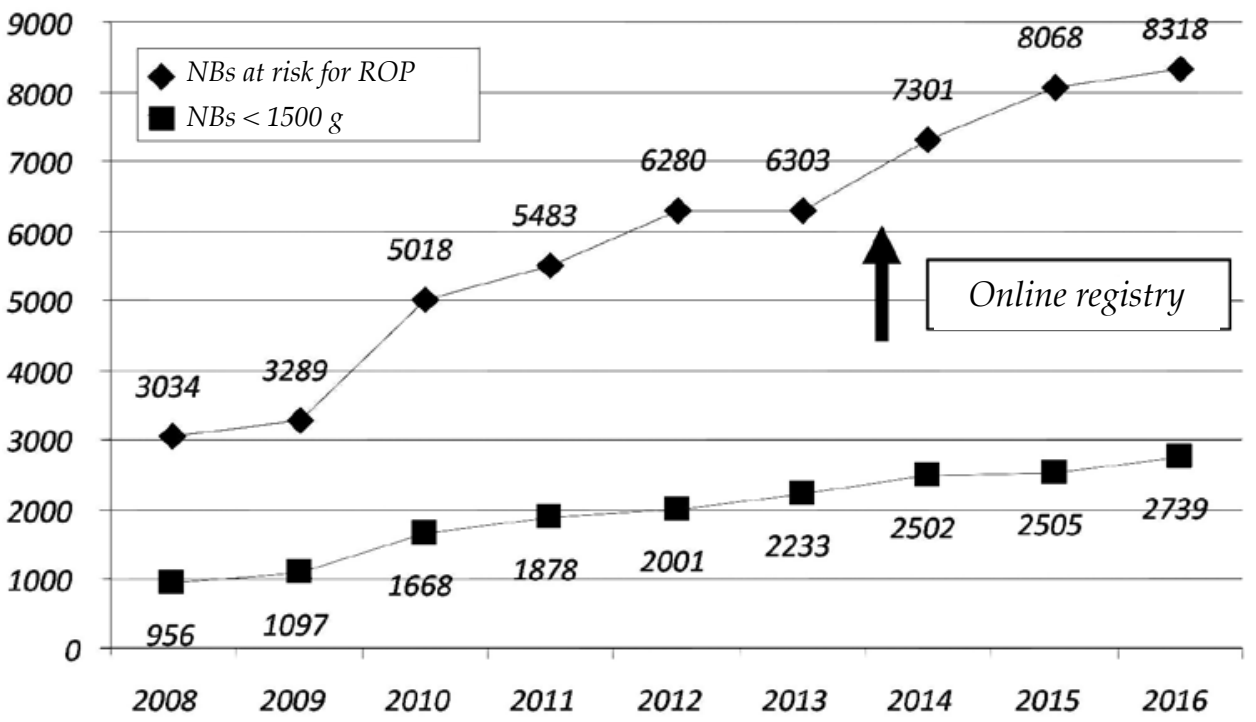

NBs: newborns.

FIGURE 3. Number of newborns with a birth weight $<1500 \mathrm{~g}$. Percentage with any retinopathy of prematurity grade and newborns treated (laser or bevacizumab)

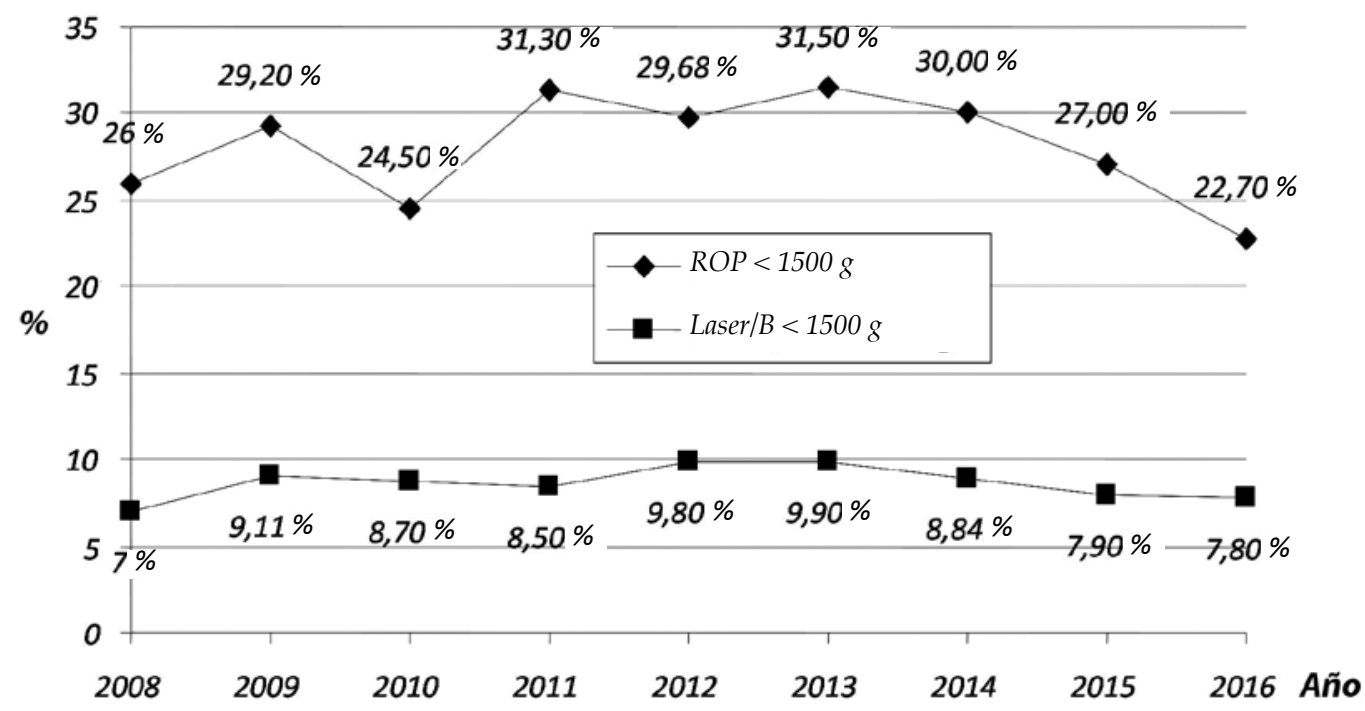

ROP: retinopathy of prematurity; B: bevacizumab. 


\section{Quality of ROP care}

Incidence of unusual cases and missed opportunities as markers of perinatal and neonatal health care markers: unusual cases reduced over time, as seen in Figure 4. In addition, missed opportunities ranged from 0 to 6 infants per year.

Figure 5 shows severe ROP cases by BW and GA in 2016. It is worth noting that, out of 253 cases, $17.3 \%$ (44 newborns) corresponded to unusual cases.

\section{DISCUSSION}

The assessment of the program implementation and results between 2004 and 2016 showed significant achievements in terms of representativeness, adherence, and scope, as well as in relation to the screening and treatment at the place of origin. However, the incidence of severe ROP among newborns with a birth weight of less than $1500 \mathrm{~g}$ is still high and the level of unusual cases and missed opportunities remains elevated, which underscores the need to strengthen the

FIGURE 4. Unusual cases: Percentage over total number of cases treated at the units participating in the program (2004-2016)

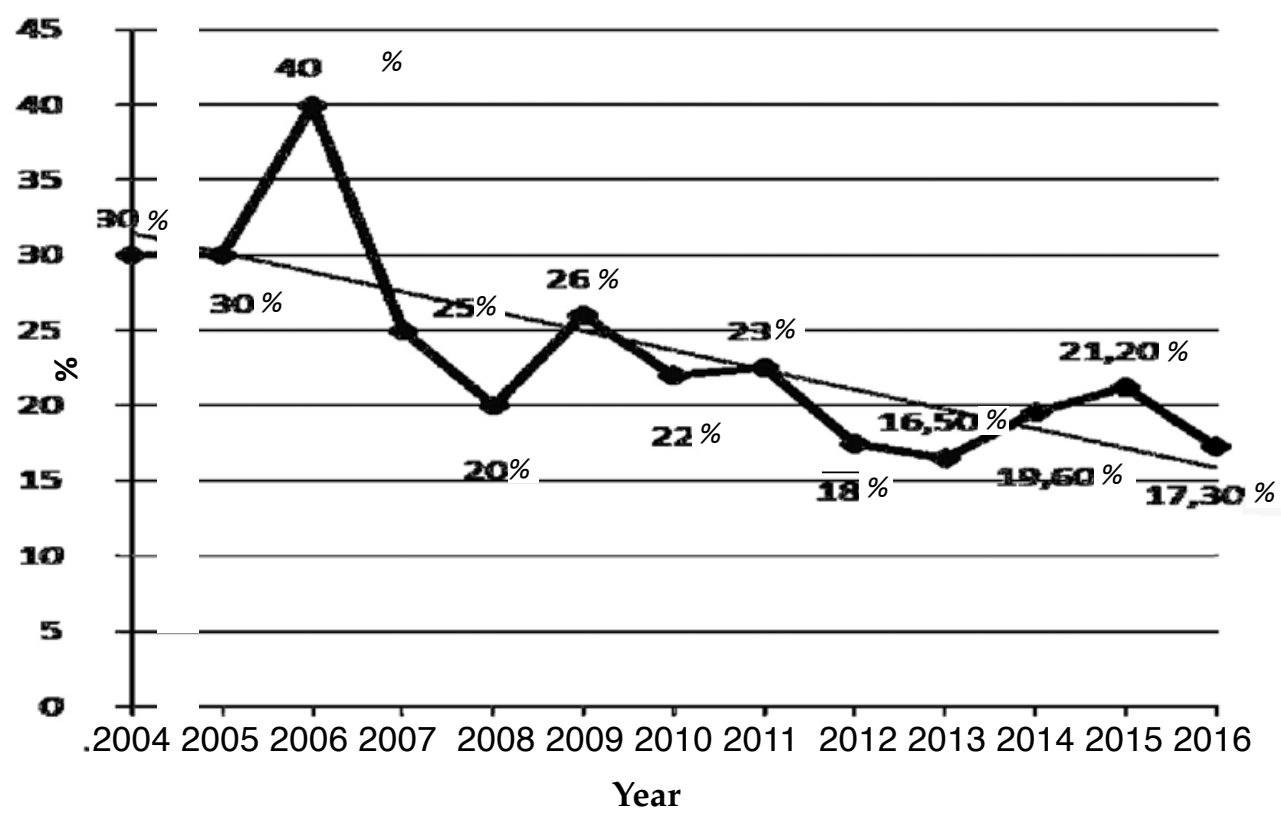

FIGURE 5. Newborns treated for retinopathy of prematurity by birth weight and gestational age in 2016. $n=253$

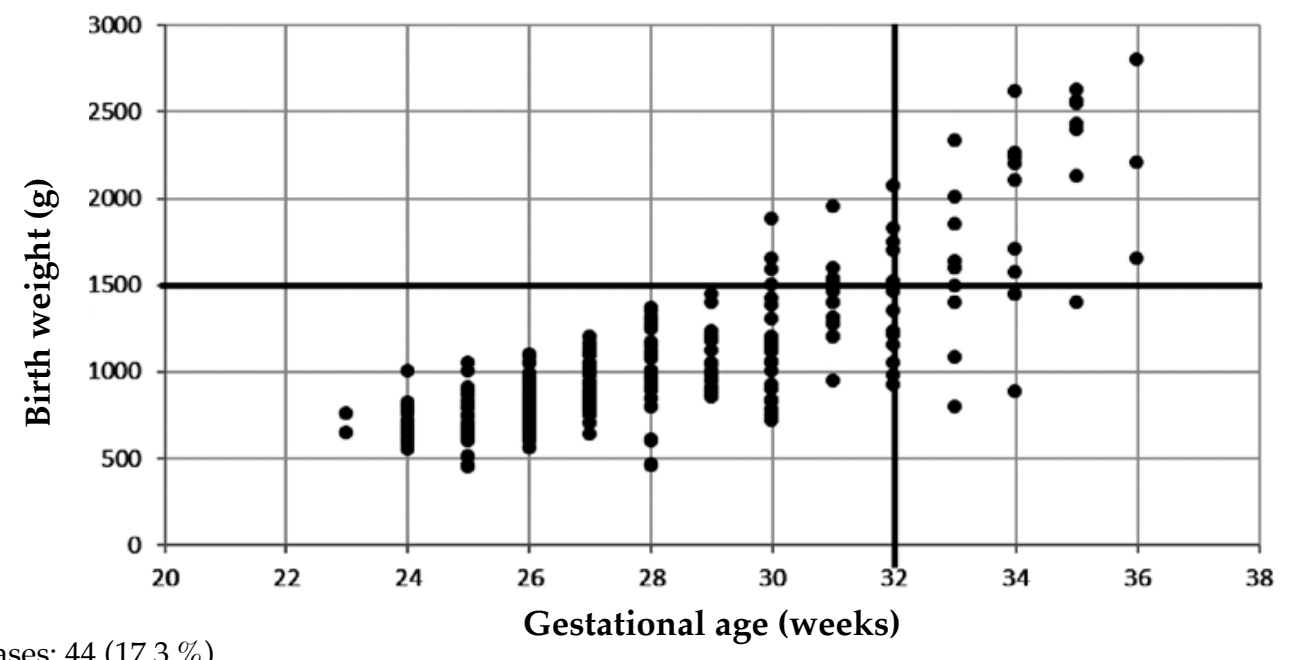

Unusual cases: $44(17.3 \%)$ 
program actions at the level of the services and outpatient follow-up.

One of the main achievements is related to the maintenance and progressive increase of adherence to the registry: if neonatal care teams from the participating facilities were not involved, it would be impossible to report the program results and review its actions.

The progressive increase of the program's representativeness is significant: it started with 14 facilities and reached 98 hospitals in 2016, covering all Argentine provinces and the Autonomous City of Buenos Aires. The introduction of ROP in the agenda of national scientific events organized by related scientific societies has helped to raise awareness of the importance of ROP prevention among neonatal care teams and to further promote the activities carried out by the ROP Argentina Group. When representativeness is analyzed in terms of participating facilities, those from the public sector clearly predominate; however, social security and private facilities, which account for $45 \%$ of all births in Argentina, are still poorly represented because they were incorporated to the program late (2014). A greater participation of social security and private facilities will allow to reveal essential information towards the strengthening of the program.

In the 13 years of the program, $\mathrm{BW}^{5}$ of newborns with ROP decreased more than $200 \mathrm{~g}$ in average and GA reduced by 3 weeks, whereas the percentage of unusual cases reduced to a half (from $30 \%$ to $17 \%$ ). Notwithstanding, the incidence of ROP, unusual cases, and missed opportunities is still high, making this the third ROP epidemic. ${ }^{6}$ Similar results have been reported in developing countries from Latin America, Asia, and Eastern Europe, ${ }^{4,7,8}$ where the longer neonatal survival resulting from technological advances at the NICUs is simultaneous with an inadequate $\mathrm{O}_{2}$ administration for therapeutic purposes, frequent nosocomial infections, blood transfusions many times, unnecessary-, and intrauterine and postnatal growth restriction, in addition to insufficient screening programs and delayed treatments. In these countries, ROP is the cause of more than $50 \%$ of childhood blindness cases.

G. Quinn et al., ${ }^{9,10}$ in an exhaustive analysis of changes observed in ROP between 1986 and 2013 in the United States of America and based on the reports of three multicenter studies in newborns with a BW of $<1251 \mathrm{~g}^{11-13}$ reported similar incidences in the diagnosis of any degree of ROP, which started at 34 weeks of adjusted age.

In Argentina, although ROP incidence has reduced, it trebles what has been reported in high-income countries with survival beyond 28 days. Severe ROP cases are not homogeneous across the different services. In a third of facilities (34/98), the incidence was above the national average, and in a fifth of them (19/98), unusual cases also exceeded the national average. In general, severe ROP and unusual cases converged at the same facilities.

In accordance with the international ROP classifications, ${ }^{14,15}$ more than $80 \%$ of cases reported in our registries corresponded to grades 1 and 2, which more commonly resolve spontaneously; however, severe ROP accounts for more than $15 \%$ of cases.

The changes in vascular endothelial growth factor (VEGF) and insulin-like growth factor-1 (IGF-1) described in ROP pathophysiology ${ }^{16,17}$ may explain the higher frequency of severe ROP in unusual cases with IUGR observed in our registries.

Although unusual cases have reduced, their incidence is still unacceptably high; a fifth of newborns with severe ROP corresponds to unusual cases. Each unusual case is a severe adverse event: a newborn with a BW $>1500 \mathrm{~g}$ and / or $\geq 32$ weeks of GA should not have signs of ROP and, least of all, require treatment.

The reasons for these may be traced back to an inadequate primary prevention of ROP since birth. $\mathrm{O}_{2}$ saturation limits -as measured by pulse oxymeters- have been defined; ${ }^{18-21}$ however, ROP leaders working at the NICUs participating in the national program have frequently reported that alarms are not turned on or correctly set.

The high incidence of severe ROP and unusual cases in a third of participating facilities compels us to reinforce actions aimed at strengthening adherence to recommendations for $\mathrm{O}_{2}$ management in these health care units. The development, publication, and dissemination of the CPG for the prevention, diagnosis, and treatment of $\mathrm{ROP}^{22}$ are true strengths of the ROP Argentina Group; however, the extent of the applicability and implementation of an unequivocal tool for the proposed objectives is unknown. Although it is very important to promote initiatives that improve personnel training in ROP management, the lack of nurse staff observed in many facilities is one of the main barriers for the primary prevention of ROP among high-risk newborns. 
One of the actual strengths of the national program is that it improved access to treatment at the same place where the baby is born. In 2004, only half of cases were treated on site, whereas, at present, a referral is not required in more than $90 \%$ of cases, with the clinical benefits this implies. The introduction of the different forms of telemedicine (RetCam, mobile phone pictures, etc.) allows to send images using virtual networks that facilitate consultation in case of diagnostic suspicion and/or treatment. ${ }^{13,23,24}$ A second opinion may prevent the unnecessary transport of high-risk children and the resulting added morbidity.

The treatment of choice for severe ROP is diode laser photocoagulation. The introduction of intravitreal anti-angiogenic drugs (bevacizumab) ${ }^{25}$ has improved the prognosis of the most severe forms of ROP (AP); however, when the recommended indication is exceeded, risks may occur because its long-term side effects are still unknown. ${ }^{26,27}$

What is the impact of the program on the eligible population in terms of childhood blindness? A partial survey conducted in 2014 (22 schools for children with severe visual impairment, 10 provinces) showed that, in 2003, $50 \%$ of enrolled children had blindness due to ROP, ${ }^{28}$ which reduced to $23 \%$ in 2013 . However, such partial reports are not enough to draw a reliable conclusion.

In 2015, the Max Planck Institute for Psycholinguistics ${ }^{29}$ defined vision as the dominant sense; children with blindness or low vision from birth will have a different emotional and social development and will adapt to the different settings of their family life; no images will be introduced in the first years of life or, at best, these will be significantly distorted; their education will require commitment and participation from their family together with committed teachers; their employability will be limited; and the high economic costs related to assistance will many times restrict their cognitive development. We propose to reduce the probability of blindness in a child to the greatest possible extent, and this justifies any health care effort made towards carrying out programs aimed specifically at the prevention, ${ }^{30}$ early diagnosis, and timely treatment of ROP.

\section{CONCLUSIONS}

Since its creation, the national program achieved improvements in access to ROP prevention and treatment in an increasing number of intensive care units of Argentina. The achievements made in relation to a timely diagnosis and treatment on site contrast with the still unacceptable number of unusual cases, which evidences the persistent failures in primary ROP prevention, especially in relation to $\mathrm{O}_{2}$ levels monitoring. Raising awareness of the background problem in relation to ROP among the health care team members and using published teaching materials will allow to reduce the risk for a child to be blind for the rest of his/her life.

\section{Acknowledgments}

We would like to thank the ROP leaders (nurses, ophthalmologists, and neonatologists) participating in the national program for providing the information necessary to develop this report and for their active work towards ROP prevention, diagnosis, and treatment. Also, we thank collaborators for developing the CPG, especially María Eugenia Esandi and Mario de Luca. We would like to thank DINAMIA for its collaboration and support to maintain the program, and the participating scientific societies (SAP, CAO, SAOI), UNICEF, and PAHO/WHO.

\section{REFERENCES}

1. Kong L, Fry M,Al-Samarraie M, et al. An update on progress and the changing epidemiology of causes of childhood blindness worldwide. J AAPOS 2012; 16(6):501-7.

2. Lomuto C. Grupo de Trabajo Colaborativo Multicéntrico: Prevención de la ceguera en la infancia por Retinopatía del Prematuro (ROP). In: Alda E, Bauer G, Benitez A, et al. Prevención de la ceguera en la infancia por Retinopatía del Prematuro ROP. Buenos Aires: Ministerio de SaludUNICEF; 2008:49-53. [Accessed on: May 30 ${ }^{\text {th }}, 2018$ ]. Available at: http: / /www.msal.gob.ar/images/stories / bes / graficos / 0000000178cnt-n04-libro-rop.pdf.

3. Darlow B. Retinopathy of prematurity: New developments bring concern and hope. I Paediatr Child Health 2015; 51(8):765-70.

4. Gilbert C, Fielder A, Gordillo L, et al. Characteristics of infants with severe retinopathy of prematurity in countries with low, moderate, and high levels of development: implications for screening programs. Pediatrics 2005; 115(5):e518-25.

5. Fenton T, Kim J. A systematic review and meta-analysis to revise the Fenton growth chart for preterm infants. $B M C$ Pediatr 2013; 13:59.

6. Alda E. Los neonatólogos, entre dos epidemias. Arch Argent Pediatr 2003; 101(4):241.

7. Quinn G. Retinopathy of prematurity blindness worldwide: phenotypes in the third epidemic. Eye Brain 2016; 8:31-6.

8. Zin A, Gole GA. Retinopathy of prematurity-incidence today. Clin Perinatol 2013; 40(2):185-200.

9. Quinn GE, Fielder AR. Prevention of ROP blindness. Clin Perinatol 2013; 40(2):xvii-xviii.

10. Quinn G, Barr C, Bremer D, et al. Changes In Course Of Retinopathy of Prematurity From 1986 To 2013: Comparison 
Of Three Studies in the United States. Ophthalmology 2016; 123(7):1595-600.

11. Cryotherapy for Retinopathy of Prematurity Cooperative Group. Multicenter Trial of Cryotherapy for Retinopathy of Prematurity. Three-month outcome. Arch Ophthalmol 1990; 108(2):195-204.

12. Early Treatment For Retinopathy Of Prematurity Cooperative Group. Revised indications for the treatment of retinopathy of prematurity: results of the early treatment for retinopathy of prematurity randomized trial. Arch Ophthalmol 2003; 121(12):1684-94.

13. Quinn GE, Ying GS, DanielE, et al. Validity of a telemedicine system for the evaluation of acute phase retinopathy of prematurity. JAMA Ophthalmol 2014; 132(10):1178-84.

14. The International Committee for the Classification of Retinopathy of Prematurity. An International Classification of Retinopathy of Prematurity. Arch Ophthalmol 1984; 102(8):1130-4

15. International Committee for the Classification of Retinopathy of Prematurity. TheInternational Classification of Retinopathy of Prematurity revisited. Arch Ophthalmol 2005; 123(7):991-9.

16. Hartnett ME, Penn JS. Mechanisms and management of retinopathy of prematurity. N Engl J Med 2012; 367(26):2515-26.

17. Hellström A, Smith LEH, Dammann O. Retinopathy of prematurity. Lancet 2013; 382(9902):1445-57.

18. SUPPORT Study Group of the Eunice Kennedy Shriver NICHD Neonatal Research Network, Carlo WA, Finer $\mathrm{NN}$, et al. Target ranges of oxygen saturation in extremely preterm infants. N Engl J Med 2010; 362(21):1959-69.

19. BOOST II UK, Australia and New Zealand Collaborative Groups, Stenson BJ, et al. Oxygen saturation and outcomes in preterm infants. N Engl J Med 2013; 368(22):2094-104.

20. SchmidtB, Whyte RK, Asztalos EV, et al. Effects of targeting higher vs lower arterial oxygen saturations on death or disability in extremely preterm infants: a randomized clinical trial. JAMA 2013; 309(20):2111-20.

21. Saugstad OD, Aune D. Optimal oxygenation of extremely low birth weight infants: a meta-analysis and systematic review of the oxygen saturation target studies. Neonatology 2014; 105(1):55-63.

22. Dirección Nacional de Maternidad, Infancia y Adolescencia. Guía de Práctica Clínica para la prevención, diagnóstico y tratamiento de la Retinopatía del Prematuro (ROP). Buenos Aires: Ministerio de Salud; 2016. [Accessed on: May 30th, 2018]. Available at: http://www.msal.gob.ar/images/ stories / bes / graficos / 0000000723cnt-guia-rop-2016.pdf.

23. Morrison D, Bothun E, Ying GS et al. Impact of number and quality of retinal images in a telemedicine screening program for ROP: results from the e-ROP study. J AAPOS 2016; 20(6):481-5.

24. Quinn G, Ells A, Capone AJr, et al. Analysis of Discrepancy Between Diagnostic Clinical Examination Findings and Corresponding Evaluation of Digital Images in the Telemedicine Approaches to Evaluating Acute-Phase Retinopathy of Prematurity Study. JAMA Ophthalmol 2016; 134(11):1263-70.

25. Mintz-Hittner HA, Kennedy KA, Chuang AZ; BEAT-ROP Cooperative Group. Efficacy of intravitrealbevacizumab for stage 3+ retinopathy of prematurity. N Engl J Med 2011; 364(7):603-15.

26. Morin J, Luu TM, Superstein R, et al. Neurodevelopmental OutcomesFollowing BevacizumabInjections for Retinopathy of Prematurity. Pediatrics 2016; 137(4):e 20153218.

27. Alda E. Uso y abuso de drogas antiangiogénicas en el tratamiento de la retinopatía del prematuro en Argentina, en 2015. Arch Argent Pediatr2016; 114(3):197-8.

28. BenítezA, Sepúlveda T, Lomuto C, etal.Severe Retinophaty of Prematurity and neonatal practice in Argentina in 2002, A national survey [abstract 3011]. Pediatric Academic Societies. 2004 May 1-4, Annual Meeting, San Fransisco, EE. UU., 2004.

29. San Roque L, Kendrick K, Norcliffe E, et al. Vision verbs dominate in conversation across cultures, but the ranking of non-visual verbs varies. Cognitive Linguistics 2015;26(1):3160.

30. Liegl R, Hellström A, Smith L. Retinopathy of prematurity: the need for prevention. Eye Brain. 2016; 8:91-102. 